\title{
Mig-6 Promotes the Apoptosis and Inhibits of the Flux of Autophagy in HCC Cell Lines Through Modulating Mig-6/miR-193a-3p/TGF- $\beta 2$ Axis
}

\section{Zixuan Li}

China Medical University First Hospital https://orcid.org/0000-0002-6972-431X

\section{Yulong Tian}

The first affiliate hospital of China medical university

Duo Hong

The First Affiliated Hospital of China Medical University

\section{Fan Wang}

The First Affiliated Hospital of China Medidal University

Hongshan Zhong ( $\nabla$ hszhong@cmu.edu.cn )

China Medical University First Hospital https://orcid.org/0000-0003-1332-5341

\section{Primary research}

Keywords: Mig-6, miRNAs, miR-193a-3p, TGF- 32 , apoptosis

Posted Date: July 9th, 2020

DOI: https://doi.org/10.21203/rs.3.rs-39528/v1

License: (9) This work is licensed under a Creative Commons Attribution 4.0 International License. Read Full License 


\section{Abstract}

Background:Mitogen-inducible gene 6 (Mig-6) is a tumor suppressor gene that plays an important role in many types of cancers by interacting with EGFR. Thus far, little is known about the molecular mechanism of Mig- 6 in hepatocellular carcinoma (HCC). Also, the relationship between Mig- 6 and miRNAs needs to be elucidated. Therefore, this study first aimed to find whether Mig- 6 could promote apoptosis and inhibition of the flux of autophagy by its downstream miRNA in HCC cell lines.

Methods: Two cell lines, HepG2and HLE, were used in this study. Mig-6 overexpression and knockdown models , miR-193a mimics and inhibitors models,were established. MiRNA microarray profiling were used to verified Mig- 6 regulated- miRNA. Real-time PCR, Western blot analysis were carried out to detect RNA and protein expression. Evaluation of fluorescent LC3 puncta and cell fow cytometer assay were used to test the autophagy and apoptosis respectively.

Results: Mig-6 induced the apoptosis and reduced the autophagy of HCC cell lines. MiR-193a-3p is a Mig6-regulated miRNA in Mig-6

overexpression model, and miR-193a-3p affected the apoptosis and autophagy of HCC cells by regulating the expression of TGF- $\beta 2$. Additionally, the relationship between Mig- 6 and transforming growth factor TGF- $\beta 2$ was explored in depth for the first time.

Conclusion:These findings revealed an important regulatory axis Mig-6/miR-193a-3p/TGF- $\beta 2$ in the apoptosis and autophagy of HCC cells, providing a novel insight into the therapeutic target in HCC.

\section{Background}

Hepatocellular carcinoma (HCC) is the most prevalent type of primary liver cancer accounting for approximately $70-90 \%$ of liver cancer cases. In terms of morbidity, it ranks the second most dominating reason for cancer-related deaths globally[1,2]. HCC is associated with high morbidity and mortality. Chronic hepatitis, especially infection induced by hepatitis, is closely related to the occurrence of HCC. Elucidating the pathogenesis of HCC can help in the early diagnosis and treatment of this disease. The mitogen-inducible gene 6 (Mig-6), also known as ERBB receptor feedback inhibitor 1 , is a transcriptionally induced EGFR inhibitor that is also a tumor suppressor[3, 4] .Mig-6 is a cytoplasmic protein that binds to the EGFR dimer interface, locking it into a catalytically inactive conformation, as well as inducing internalization and degradation of EGFR via a lysosomal mechanism[5] .The expression of Mig-6 has been demonstrated to be suppressed in liver cancer tissues, leading to increased EGFR-AKT signaling and enhanced cell migration [6].Mig-6 has also been reported to regulate the proliferation of liver cancer cells through the classic EGFR pathway. However, some of the regulatory effects of Mig-6 on HCC cells, such as the effect on HCC autophagy, cannot be explained by the classic EGFR pathway, forcing the exploration of new functions of Mig-6. 
MicroRNAs (miRNAs) are small noncoding RNA molecules with 19-22 nucleotides that regulate the protein expression[7] They regulate the gene expression at the posttranscriptional level by decreasing the stability or inhibition of translation of messenger RNAs (mRNAs) through targeting the 3 '-untranslated region of mRNAs[8].

Increasing or decreasing the levels of specific miRNAs can result in aberrant protein expression, leading to the critical change in cell functions; for example, proliferation, cell cycle, apoptosis, and invasion. Many studies showed that miRNAs participated in the biological behavior of HCC. For instance, miR-139-5p influenced HCC cell invasion and proliferation capacities by decreasing the expression of SLITRK4[9]. MiR-133b promotes cell proliferation and metastasis in HCC by regulating SF3B4[10]. The downregulated expression of miR-193a-3p was reported in many types of cancers, including non-small-cell lung cancer (NSCLC)[11],colorectal cancer[12]and breast cancer[13]. MiR-193a-3p was also related to the proliferation, migration, invasion, and apoptosis of liver cancer cells[14-16]. Therefore, the potential mechanism of miR-193a-3p in HCC needs to be explored.

In this study, the enhanced expression of Mig-6 in vitro was found to not only weaken the flux of autophagy but also promote the apoptosis of HCC cells. The miRNA expression profiling chips were adequately applied, and three bioinformatics algorithms were used to screen out its potential downstream target miR-193a-3p and transforming growth factor (TGF)- $\beta 2$. Afterward, the impact of miR193a-3p on the apoptosis and autophagy of HCC was studied and evaluated. Finally, the indirect control of Mig- 6 and TGF- $\beta 2$ was studied in depth for the first time, providing a novel insight into the Mig-6-based therapeutic approach to treat human HCC.

\section{Materials And Methods}

\section{Cell lines}

Human hepatocellular cancer cell lines HepG2, Hep3B, PLC/PRF/5, HLE, and HuH7were maintained in Dulbecco's modified Eagle's medium (Biological Industries) supplemented with $10 \%$ fetal calf serum (Biological Industries), $10 \mathrm{lU} / \mathrm{mL}$ penicillin (Sigma, St.Louis, MO), and $100 \mathrm{mg} / \mathrm{mL}$ streptomycin (Sigma).Cells were grown on sterile T25 cell culture flask (Corning) and were passaged every $2-3 \mathrm{~d}$ using $0.25 \%$ trypsin (Biological Industries).

\section{Transfecton of expression plasmids,RNAi, miRNA mimics,and}

\section{inhibitors}

The cells were seeded in 6-well plates $24 \mathrm{~h}$ prior to the experiment. Plasmids control vector (pcDNA3) and Mig-6 overexpression vector ( Takara Biotechnology, Dalian, China),(TGF-32over expression vector (OriGene Technologies Inc $₫$ Rockville, MDロUSA),RNAi for Mig-6 and non-targeting siRNA (GenePharma, Shanghai, China), miR-193a mimics, miR-193a inhibitors,mimic control,and inhibitor 
control[RIBOBIO,Guangzhou, China) were all using Lipofectamine 3000(Invitrogen, Carlsbad, CA, USA).according to the manufacturer's protocol. The mRNA and protein levels were assessed $48 \mathrm{~h}$ following transfection.

\section{Quantitative real-time PCR}

Assays to quantify miR-193a-3p were performed using TaqMan miRNA probes and TaqMan ${ }^{\circledR}$ MicroRNA Assays (Applied Biosystems, Foster City, CA, USA) according to the manufacturer's instructions. The reactions as follows: $95^{\circ} \mathrm{C}$ for $5 \mathrm{~min}, 40$ cycles of $95^{\circ} \mathrm{C}$ for $15 \mathrm{~s}, 60^{\circ} \mathrm{C}$ for 1 min.Quantitative theTGF- $\beta 2$ mRNA levels was performed using SsoFast ${ }^{\mathrm{TM}}{ }^{\mathrm{E}} \mathrm{V} a \mathrm{Green}{ }^{\circledR}$ Supermix (Bio-rad). The reactions as follows: $95^{\circ} \mathrm{C}$ for $30 \mathrm{~s}, 40$ cycles of $95^{\circ} \mathrm{C}$ for $5 \mathrm{~s}, 60^{\circ} \mathrm{C}$ for $20 \mathrm{~s}$. Light Cycler ${ }^{\circledR} 480 \otimes($ Roche) was used to perform the real-time PCR.The primer sequences are provided below:

TGF- $\beta 2$ (forward)CATCCCGCCCACTTTCTAC;

TGF- $\beta 2$ (reverse) TCCGTTGTTCAGGCACTCT;

Actin (forward) ATAGCACAGCCTGGATAGCAACGTAC;

Actin (reverse)CACCTTCTACAATGAGCTGCGTGTG.

Experiments were repeated in triplicate.

\section{Western blot analysis.}

Total proteins from cell lines were extracted in a lysis buffer (CAT.78510) (Thermo Fisher Scientific, Rockford, IL) and quantified using Bradford method (CAT.23226) (Thermo Fisher Scientific). Sixty micrograms of protein were separatedby $12 \%$ SDS-PAGE (Bio-Rad, USA). After transferring by Trans-Blo ${ }^{\circledR}$ Turbo $^{\text {TM }}$ (Bio-Rad, USA), the polyvinylidene fluoride (PVDF) membranes (Millipore, Billerica, MA, USA) were incubated overnight at $4{ }^{\circ} \mathrm{C}$ with the following antibodies Mig-6 (1: 1000, CAT.11630-1-AP) (protein tech), anti-P62 (1:1000,CAT.55274-1-AP) (protein tech), anti-LC3b (1:2000, CAT.NB100-2220) (Novus Biologicals USA),anti-TGF- $\beta 2$ (1:1000,CAT.ab36495) (Abcam), $\beta$-actin (1:1000, CAT.20536-1-AP) (protein tech). After incubation with peroxidase-coupled anti-mouse or rabbit IgG (Zhongshan jinqiao,China) at $37^{\circ} \mathrm{C}$ for 2 hours. An enhanced chemiluminescence (ECL) detection system (Bio-Rad, USA) was used to visualize signals following standard protocols. $\beta$-actin served as an endogenous protein control for normalization.

\section{Cell apoptosis experiments.}

Apoptosis was detected using an Annexin V-FITC/PI double staining kit (Dojindo, Gaithersburg, MD, USA). Cells that incubated in 12-well plates were collected by Accutase(Multi sciences, China) after $48 \mathrm{~h}$ transfection and washed twice with cold phosphate-buffered saline (PBS) by gentle shaking. Cells were then resuspended and added to binding buffer (1X); cell density was adjusted to $1 \times 106$ cells $/ \mathrm{ml}$. In the dark, $5 \mu \mathrm{l}$ Annexin V-FITC and $5 \mu \mathrm{l}$ PI Solution were added to the cell suspension volume of $100 \mu \mathrm{l}$ and incubated for $15 \mathrm{~min}$ at room temperature before the addition of $400 \mu$ l binding buffer (1X). Ten thousand 
events per sample were acquired using a FACScan flow cytometer and the percentage of cell apoptosis was analyzed using BD Accuri ${ }^{\mathrm{TM}}$ software (both from Becton-Dickinson, San Jose, CA, USA).

\section{Evaluation of fluorescent LC3 puncta}

LC3 puncta were indicated by mRFP-GFP-LC3 adenovirus (Gene Chem, Shanghai, China) Briefly, cells were transfected with mRFP-GFP-LC3 for $48 \mathrm{~h}$ before receiving Transfection treatments. After 24 -hours Transfection treatment, cells were observed under a fluorescence microscopy (Nikon). Ten views were examined per slide and the images were acquired.

miRNA microarray profiling and analysis.

Total RNA was extracted with the use of TRIzol reagent (Invitrogen, Carlsbad, CA, USA). Human miRNA Microarray(GeneChip miRNA 4.0,Affymetrix)was used for microRNA profiling. The quality of total RNA was evaluated by measuring the ratio of A260/A280 on an ultraviolet pectrophotometer (NanoDrop 2000囚Thermo) and by Checking the integrity and purity with a nucleic acid electrophoresis analyzer (Agilent 2100 Bioanalyzer )Biotin-labeled complementary RNA (cRNA) generated by in vitrotranscription reactions(Affymetrix, USA) was fragmented and hybridized with GeneChip Hybridization Oven 645(Affymetrix, USA) at $45^{\circ} \mathrm{C}$ for $16 \mathrm{~h}$.After hybridization, the arrays were washed, stained with GeneChip ${ }^{\text {TM }}$ Hybridization, Wash, and Stain Kit (Thermo Fisher Scientific) and scanned using an Affymetrix GeneChip Scanner 3000 .After normalization and background filtration, the differentially expressed genes were analyzed.Using TargetScan,microRNA.ORG and miRDB software for target gene prediction.

\section{Result}

Mig-6 induced the apoptosis and reduced the autophagy of HCC cell lines.

To validate the role of Mig- 6 in HCC cell lines,we examined the impact exerted by increasing Mig- 6 on HCC cell apoptosis and autophagy with Mig- 6 plasmid.HepG-2 and HLE cells were transfected with Mig- 6 plasmid, respectively. As expected, two cell lines transfected with Mig- 6 showed the enhanced percentage of apoptosis(Fig. 1a). In the meanwhile western blotting were using for evaluated the expression levels of autophagy-associated protein (Fig. 1b). The expression levels of p62, which is mainly degraded by autophagy pathway, is greatly induced in the Mig-6 plasmid groups compared with those of the PC groups. But microtubule associated protein 1 light chain $3 \beta$ (LC3b), following transfection with Mig- 6 plasmid were significantly decreased. Autophagic flux experiment showed that in two cell lines, Mig-6 plasmid weakened the flux of autophagy, with a less number of autophagosomes (yellow) and autolysosomes (red) in two celllines(Fig. 1c).

\section{Identification of Mig-6-regulated miRNAs}

Several underlying mechanisms of Mig- 6 were hypothesized; the regulation of miRNAs by Mig- 6 was an area that had never been studied. Mig-6-regulated miRNAs were identified by transducing 293T with 
lentiviruses encoding control virus or lentivirus-mediated Mig-6 (Gene Chem, Shanghai, China). After transduction for $48 \mathrm{~h}$, the cells were treated with puromycin for $48 \mathrm{~h}$ to remove the nontransduced cells. Successful transduction was examined by fluorescence microscopy of GFP-expressing cells (Fig. 2a), which was further confirmed by western blot analysis (Fig. 2b). The GFP-positive cell population was used immediately for analysis using the GeneChip assay. The results showed that a total of $44 \mathrm{Mig}-6-$ regulated miRNAs were identified, of which 11 were upregulated and 33 downregulated (Fig. 2c).Among them the expression of 4 and 16 miRNAs in Mig-6 overexpressed cells was increased or inhibited by more than 2.5-fold, respectively (Table 1). Among all the miRNAs, miR-193a-3p is the most potent, with downregulated expression reported in many types of cancers. The HepG-2 and HLE cells were transfected with Mig-6 plasmid and siRNA to further verify the relationship between Mig-6 and miR-193a-3p. The transfection efficiency was measured using Western blot analysis (Fig. 3a). When the expression of Mig-6 was promoted, the miR-193a-3p level correspondingly increased in each cell line, and when the expression of Mig-6 was suppressed, the decrease in the miR-193a-3p was observed (Fig. 3b). 
Table 1

Expression changes of Mig6-regulated miRNAs

\begin{tabular}{|lll|}
\hline miRNA & Regulation & $\begin{array}{l}\text { Control virus or LV-Mig-6 } \\
\text { Fold change }\end{array}$ \\
\hline hsa-miR-1269a & up & 3.663214041 \\
\hline hsa-miR-193a-3p & up & 2.960149418 \\
\hline hsa-miR-1244 & up & 2.512778203 \\
\hline hsa-miR-371b-5p & up & 2.503430956 \\
\hline hsa-miR-5093 & down & -5.363445158 \\
\hline hsa-miR-297 & down & -4.571560354 \\
\hline hsa-miR-4793-3p & down & -4.556744037 \\
\hline hsa-miR-610 & down & -4.539741026 \\
\hline hsa-miR-4440 & down & -4.535851264 \\
\hline hsa-miR-195-3p & down & -4.458473988 \\
\hline hsa-miR-6877-3p & down & -4.173369522 \\
\hline hsa-miR-3148 & down & -3.956889197 \\
\hline hsa-miR-8071 & down & -3.647623099 \\
\hline hsa-miR-185-3p & down & -3.48629987 \\
\hline hsa-miR-3064-5p & down & -3.347459653 \\
\hline hsa-miR-595 & down & -3.344313283 \\
\hline hsa-miR-3907 & down & -3.319532324 \\
\hline hsa-miR-7844-5p & down & -2.856073948 \\
\hline hsa-miR-4455 & down & -2.736743073 \\
\hline hsa-mir-297 & down & -2.606974853 \\
\hline
\end{tabular}

MiR-193a-3p induced the apoptosis and reduced the autophagy of HCC cell lines.

MiR-193a-3p is reported to relate to various pathological processes of liver cancer, including proliferation, migration, invasion, apoptosis, radioresistance, and chemotherapeutic tolerance. However, the relationship between miR-193a-3p and autophagy has not been reported to date. This study attempted to clarify the impact exerted by miR-193a-3p. First, the HepG-2 and HLE cells were transfected with miR193a-3p mimics or miR-193a-3p inhibitors, and the transfection efficiency was measured by reverse transcription-polymerase chain reaction (Fig. 4a). Then, apoptosis was inspected in the HepG-2 and HLE 
cells with flow cytometric analysis. A larger percentage of apoptotic cells were presented in the cells transfected with miR-193a-3p mimics; however, miR-193a-3p inhibitors decreased the apoptotic rate (Fig. 4b ,c). Finally, the effect of miR-193a-3p on the autophagy capacity of HepG-2 and HLE cells was verified using western blot analysis and autophagic flux experiment. As anticipated, miR-193a-3p mimics increased the expression of p62 but reduced the expression of LC3b, as well as weakened the flux of autophagy. The reverse consequence was also observed in the miR-193a-3p inhibitor group (Fig. 4d,e).

\section{MiR-193a-3p affected the apoptosis and autophagy of HCC cells by regulating the expression of TGF- $\beta 2$.}

The miR-193a-3p target predicted by all three target gene prediction software was regarded with high confidence (Table S1). Thus, 62 nominated target genes were hit by miR-193a-3p. Among them, the TGF$\beta 2$ gene gained attention. Previous studies reported that TGF- $\beta 2$ was regulated by multiple miRNAs and associated with apoptosis and autophagy in certain cell lines. In this study, the expression of TGF- $\beta 2$ protein in both HepG-2 and HLE cells decreased after the transfection of miR-193a-3p mimics, whereas treatment with miR-193a-3p inhibitors increased the expression of TGF- $\beta 2$ (Fig. 5a). TGF- $\beta 2$ mRNA was also quantified after transfecting miR-193a-3p mimics or inhibitors into HCC cells, but no statistically significance difference was found at the mRNA level (Fig. 5b). Next, the apoptosis and autophagy were applied to assess the impact of miR-193a-3p and TGF- $\beta 2$ on HCC. The HepG-2 and HLE cells transfected with miR-193a-3p mimics showed an increased percentage of apoptotic cells and weakened flux of autophagy. However, TGF- $\beta 2$ plasmid could not only inhibit apoptosis and enhance the flux of autophagy but also weaken the effects exerted by miR-193a-3p mimics (Fig. 5c,d,e). These results substantiated that miR-193a-3p affected the apoptosis and autophagy of HCC cells by controlling the expression of TGF- $\beta 2$.

\section{Mig-6 modulated apoptosis and autophagy of HCC cells through the miR-193a-3p/TGF- $\beta 2$ pathway.}

The relationship between Mig- 6 and TGF- $\beta 2$ has not been reported to date. Therefore, the correlation between Mig- 6 and TGF- $\beta 2$ protein level was analyzed in five HCC cell lines. An inverse relationship was observed between the expression of Mig- 6 and TGF- 32 . High expression of Mig- 6 was found in Huh7 and PLC/PRF/ 5 cells; both of them showed low levels of TGF- $\beta 2$. On the contrary, the HepB3 and HLE cells with the low level expression of Mig-6 had high expression of TGF- 32 (Fig. 6a). A series of function experiments were performed in HepG-2 and HLE cells to assess further impacts of overexpression of Mig6. As indicated by western blot analysis, the level of TGF- $\beta 2$ protein decreased after HCC cells were transfected with Mig-6 plasmid (Fig. 6b,c), without any mRNA alteration (data not show). Meanwhile, miR-193a-3p reversed the decrease in TGF- $\beta 2$ induced by the Mig-6 plasmid (Fig. 6b,c). As presented in Fig. 1A, a larger percentage of apoptotic cells were present in the cells transfected with Mig-6 plasmid compared with the control group, whereas they were rescued by miR-193a-3p inhibitors (Fig. 6d). The autophagy of HCC cells was tested by western blot analysis and autophagic flux assay. Weakened autophagy due to the overexpression of Mig-6 was reversed by miR-193a-3p inhibitors (Fig. 6b,c,e).

\section{Discussion}


Autophagy is a tightly regulated and highly conserved lysosomal degradation pathway for the degradation of long-lived proteins and cytoplasmic organelles. Recent accumulating data point to autophagy as a key player in various human diseases, such as cancer[17] .Apoptosis is the process by which a cell ceases to grow and divide, resulting in the controlled death of the cell. The initiation of apoptosis depends on the activation of a series of cysteine-aspartic proteases known as caspases [18]. Autophagy correlates with apoptosis. For example, the autophagy of damaged organelles can repair the injury to a small number of mitochondria; however, if a sufficiently large number of mitochondria are damaged, the intrinsic pathway of apoptosis is activated following the high levels of released cytochrome C[19]. This study demonstrated that Mig-6 promoted the apoptosis of HCC cells, combined with the inhibition of the flux of autophagy. Therefore, Mig- 6 might exert its role by regulating the dynamic balance between apoptosis and autophagy in HCC cells.

As reported, Mig- 6 could be regulated by certain miRNAs[20-23], Especially miR-589-5p and miR-374a, regulated the proliferation of HCC cells by targeting Mig-6[24, 25]. These studies stimulated the interest in exploring whether Mig-6 could affect the changes in miRNAs. The miRNA microarray profiling was used to identify miRNAs specifically regulated by Mig-6. A total of 44 Mig-6-regulated miRNAs were identified, of which 11 were upregulated and 33 downregulated (Figure S1). Among these miRNAs, four miRNAs were upregulated more than 2.5 times by Mig-6, and miR-193a-3p was one of them.

MiR-193a-3p is reported as a tumor suppressor in many types of cancers. It inhibits the migration and invasiveness of NSCLC[26]. In colorectal cancer, miR-193a-3p inhibited cell proliferation and promoted the apoptosis[27]. MiR-193a-3p suppressed ovarian cancer cell growth and migratory/invasive capacities[28]. MiR-193a-3p had also been proven to be related to the migration and invasion[14], proliferation and apoptosis $[15,16]$, radioresistance, and chemotherapeutic tolerance in $\operatorname{HCC}[29,30]$. In addition, the expression of miR-193a-3p was identified as a predictor of HCC progression-free survival[31]. These results demonstrated the important role of miR-193a-3p in HCC. In this study, miR193a-3p mimics induced a high level of apoptosis in HCC cell lines; however, miR-193a-3p inhibitors decreased the apoptotic rate, which was consistent with the previous findings. Also, the autophagy capacity of HCC cell lines was found to be weakened by miR-193a-3p mimics, whereas miR-193a-3p inhibitor could enhance the flux of autophagy. All these findings confirmed that miR-193a-3p had an anticancer effect on HCC by influencing cell autophagy and apoptosis in vitro.

Numerous targets of miR-193a-3p have been reported[26, 28, 32, 33]. In this study, the TargetScan, miRNA.ORG, and miRDB software were used for the prediction of target genes. Finally, TGF- $\beta 2$ was selected, which might play an important role in HCC as the target of miR-193a-3p. TGF- $\beta$ has three different isoforms: TGF- $\beta 1$, TGF- $\beta 2$, and TGF- $\beta 3$, with similar but not identical biologic activities[34]. The role of TGF- $\beta$ signaling in HCC progression is not completely understood. Immunosuppression induced by TGF- $\beta 2$ was assumed to be the main mechanism through which tumor cells could escape from immune surveillance[35]. TGF- $\beta 2$ was upregulated in liver disease, suggesting it to be a promising therapeutic target for tackling fibrosis and HCC[36]. Exogenous TGF- $\beta 2$ resulted in a significant elevation of the epithelial to mesenchymal transition by enhancing autophagic flux in HCC[37]. This study eventually 
concluded that the upregulation of TGF- $\beta 2$ could inhibit apoptosis and promote the autophagic flow of HCC cells. It also confirmed the inverse correlation between Mig- 6 and TGF- $\beta 2$.

This study had certain limitations. First, the clinical significance of the interaction among Mig-6, miR193a-3p, and TGF- 32 in HCC needed to be analyzed, which could increase the value of Mig-6, miR-193a$3 p$, and TGF- $\beta 2$ in the diagnosis. Second, the overexpression of Mig- 6 or Mig- 6 gene knockout mice could be applied to verify the Mig-6/miR-193a-3p/TGF- $\beta 2$ axis in vivo. Third, many miRNAs regulated by Mig-6 were also found in this study, but their mechanism was not studied. Subsequent experiments need to explore the new functions of Mig-6-regulated miRNAs in HCC and provide new perspectives on the treatment of HCC.

\section{Conclusion}

Taken together, our data verified that Mig- 6 and miR-193a-3p as the tumor suppressors in HCC, which can promote the apoptosis and inhibition of the flux of autophagy by targeting TGF- $\beta 2$. The Mig- 6 regulated miRNAs and the correlation between Mig- 6 and TGF- $\beta 2$ were also confirmed in HCC for the first time. This article provided clues for an important Mig-6/miR-193a-3p/TGF- $\beta 2$ regulatory axis, providing more perspectives on the treatment of HCC.

\section{Declarations}

\section{Authors' contributions}

ZXL, YLT and HSZ designed the study;ZXL, YLT, DH and FW performed the experiments and prepared the fgures;ZXL and HSZ contributed to draft ing the manuscript. All authors read and approved the fnal manuscript.

\section{Author details}

1Key Laboratory of Diagnostic Imaging and Interventional Radiology of Liaoning Province, The First Affiliated Hospital of China Medical University, Shenyang, P. R. China

2Department of Interventional Radiology, The First Affiliated Hospital of China Medical University, Shenyang, People's Republic of China.

\section{Acknowledgements}

We thank International Science Editing ( http://www.internationalscienceediting.com ) for editing this manuscript.

\section{Competing interests}


The authors declare that they have no competing interests.

\section{Availability of data and materials}

The datasets used and/or analyzed during the current study are available from

the corresponding author on reasonable request.

\section{Consent for publication}

Not applicable.

\section{Ethics approval and consent to participate}

The study was approved by the Ethics Review Committee of The First Affiliated Hospital of China Medical University(Shenyang, China).

\section{Funding}

This study was supported by grants from the National Natural Science Foundation of China (No. 81501564) \National Key R\&D Program of China (No. 2018YFC0115500)هLiaoNing Revitalization Talents Program(No. XLYC1802098).

\section{References}

1. Torre LA, Bray F, Siegel RL, Ferlay J, Lortet-Tieulent J, Jemal A. Global cancer statistics, 2012. Cancer J Clin. 2015;65(2):87-108.

2. Schoenberg MB, Hao J, Bucher JN, Miksch RC, Anger HJW, Mayer B, et al. Perivascular TumorInfiltrating Leukocyte Scoring for Prognosis of Resected Hepatocellular Carcinoma Patients. Cancers. 2018;10(10).

3. Kim TH, Lee DK, Cho SN, Orvis GD, Behringer RR, Lydon JP, et al. Critical tumor suppressor function mediated by epithelial Mig-6 in endometrial cancer. Cancer research. 2013;73(16):5090-9.

4. Ying $H$, Zheng $H$, Scott $K$, Wiedemeyer $R$, Yan $H$, Lim C, et al. Mig- 6 controls EGFR trafficking and suppresses gliomagenesis. Proc Natl Acad Sci USA. 2010;107(15):6912-7.

5. Frosi Y, Anastasi S, Ballaro C, Varsano G, Castellani L, Maspero E, et al. A two-tiered mechanism of EGFR inhibition by RALT/MIG6 via kinase suppression and receptor degradation. J Cell Biol. 2010;189(3):557-71.

6. Reschke M, Ferby I, Stepniak E, Seitzer N, Horst D, Wagner EF, et al. Mitogen-inducible gene-6 is a negative regulator of epidermal growth factor receptor signaling in hepatocytes and human hepatocellular carcinoma. Hepatology. 2010;51(4):1383-90.

7. Jansson MD, Lund AH. MicroRNA and cancer. Molecular oncology. 2012;6(6):590-610. 
8. He L, Hannon GJ. MicroRNAs: small RNAs with a big role in gene regulation. Nature reviews Genetics. 2004;5(7):522-31.

9. Wu J, Zhang T, Chen Y, Ha S. MiR-139-5p influences hepatocellular carcinoma cell invasion and proliferation capacities via decreasing SLITRK4 expression. Bioscience reports. 2020;40(5).

10. Liu Z, Li W, Pang Y, Zhou Z, Liu S, Cheng K, et al. SF3B4 is regulated by microRNA-133b and promotes cell proliferation and metastasis in hepatocellular carcinoma. EBioMedicine. 2018;38:5768.

11. Heller G, Weinzierl M, Noll C, Babinsky V, Ziegler B, Altenberger C, et al. Genome-wide miRNA expression profiling identifies miR-9-3 and miR-193a as targets for DNA methylation in non-small cell lung cancers. Clinical cancer research: an official journal of the American Association for Cancer Research. 2012;18(6):1619-29.

12. Yong FL, Law CW, Wang CW. Potentiality of a triple microRNA classifier: miR-193a-3p, miR-23a and miR-338-5p for early detection of colorectal cancer. BMC Cancer. 2013;13:280.

13. Tahiri A, Leivonen SK, Luders T, Steinfeld I, Ragle Aure M, Geisler J, et al. Deregulation of cancerrelated miRNAs is a common event in both benign and malignant human breast tumors. Carcinogenesis. 2014;35(1):76-85.

14. Qian YY, Li K, Liu QY, Liu ZS. Long non-coding RNA PTENP1 interacts with miR-193a-3p to suppress cell migration and invasion through the PTEN pathway in hepatocellular carcinoma. Oncotarget. 2017;8(64):107859-69.

15. Zhou HL, Zhou YF, Feng ZT. Long noncoding RNA ZFAS1 promotes hepatocellular carcinoma proliferation by epigenetically repressing miR-193a-3p. Eur Rev Med Pharmacol Sci. 2019;23(22):9840-7.

16. Wang SS, Huang ZG, Wu HY, He RQ, Yang LH, Feng ZB, et al. Downregulation of miR-193a-3p is involved in the pathogenesis of hepatocellular carcinoma by targeting CCND1. PeerJ. 2020;8:e8409.

17. Devis-Jauregui L, Eritja N, Davis ML, Matias-Guiu X, Llobet-Navas D. Autophagy in the physiological endometrium and cancer. Autophagy. 2020:1-19.

18. Poon IK, Lucas CD, Rossi AG, Ravichandran KS. Apoptotic cell clearance: basic biology and therapeutic potential. Nature reviews Immunology. 2014;14(3):166-80.

19. Jaeschke H, Lemasters JJ. Apoptosis versus oncotic necrosis in hepatic ischemia/reperfusion injury. Gastroenterology. 2003;125(4):1246-57.

20. Guo Y, Tian L, Liu X, He Y, Chang S, Shen Y. ERRFI1 Inhibits Proliferation and Inflammation of Nucleus Pulposus and Is Negatively Regulated by miR-2355-5p in Intervertebral Disc Degeneration. Spine. 2019;44(15):E873-81.

21. Wang $W$, Zheng $Y$, Wang M, Yan M, Jiang J, Li Z. Exosomes derived miR-126 attenuates oxidative stress and apoptosis from ischemia and reperfusion injury by targeting ERRFI1. Gene. 2019;690:7580.

22. Migliore C, Morando E, Ghiso E, Anastasi S, Leoni VP, Apicella M, et al. miR-205 mediates adaptive resistance to MET inhibition via ERRFI1 targeting and raised EGFR signaling. EMBO molecular 
medicine. 2018;10(9).

23. Santra M, Chopp M, Santra S, Nallani A, Vyas S, Zhang ZG, et al. Thymosin beta 4 up-regulates miR200a expression and induces differentiation and survival of rat brain progenitor cells. Journal of neurochemistry. 2016;136(1):118-32.

24. Xu M, Wang Y, He HT, Yang Q. MiR-589-5p is a potential prognostic marker of hepatocellular carcinoma and regulates tumor cell growth by targeting MIG-6. Neoplasma. 2018;65(5):753-61.

25. Li H, Chen H, Wang H, Dong Y, Yin M, Zhang L, et al. MicroRNA-374a Promotes Hepatocellular Carcinoma Cell Proliferation by Targeting Mitogen-Inducible Gene 6 (MIG-6). Oncology research. 2018;26(4):557-63.

26. Liu X, Min S, Wu N, Liu H, Wang T, Li W, et al. miR-193a-3p inhibition of the Slug activator PAK4 suppresses non-small cell lung cancer aggressiveness via the p53/Slug/L1CAM pathway. Cancer letters. 2019;447:56-65.

27. Zhu Z, Du S, Yin K, Ai S, Yu M, Liu Y, et al. Knockdown long noncoding RNA nuclear paraspeckle assembly transcript 1 suppresses colorectal cancer through modulating miR-193a-3p/KRAS. Cancer medicine. 2019;8(1):261-75.

28. Chen K, Liu MX, Mak CS, Yung MM, Leung TH, Xu D, et al. Methylation-associated silencing of miR193a-3p promotes ovarian cancer aggressiveness by targeting GRB7 and MAPK/ERK pathways. Theranostics. 2018;8(2):423-36.

29. Ma H, Yuan L, Li W, Xu K, Yang L. The LncRNA H19/miR-193a-3p axis modifies the radio-resistance and chemotherapeutic tolerance of hepatocellular carcinoma cells by targeting PSEN1. Journal of cellular biochemistry. 2018;119(10):8325-35.

30. Ma K, He Y, Zhang H, Fei Q, Niu D, Wang D, et al. DNA methylation-regulated miR-193a-3p dictates resistance of hepatocellular carcinoma to 5-fluorouracil via repression of SRSF2 expression. J Biol Chem. 2012;287(8):5639-49.

31. Qin L, Huang J, Wang G, Huang J, Wu X, Li J, et al. Integrated analysis of clinical significance and functional involvement of microRNAs in hepatocellular carcinoma. Journal of cellular physiology. 2019;234(12):23581-95.

32. Liu L, Li Y, Liu S, Duan Q, Chen L, Wu T, et al. Downregulation of miR-193a-3p inhibits cell growth and migration in renal cell carcinoma by targeting PTEN. Tumour biology: the journal of the International Society for Oncodevelopmental Biology Medicine. 2017;39(6):1010428317711951.

33. Kong L, Wei Q, Hu X, Chen L, Li J. miR-193a-3p Promotes Radio-Resistance of Nasopharyngeal Cancer Cells by Targeting SRSF2 Gene and Hypoxia Signaling Pathway. Medical science monitor basic research. 2019;25:53-62.

34. Matsuzaki K, Date M, Furukawa F, Tahashi Y, Matsushita M, Sugano Y, et al. Regulatory mechanisms for transforming growth factor beta as an autocrine inhibitor in human hepatocellular carcinoma: implications for roles of smads in its growth. Hepatology. 2000;32(2):218-27.

35. Maggard M, Meng L, Ke B, Allen R, Devgan L, Imagawa DK. Antisense TGF-beta2 immunotherapy for hepatocellular carcinoma: treatment in a rat tumor model. Ann Surg Oncol. 2001;8(1):32-7. 
36. Dropmann A, Dediulia T, Breitkopf-Heinlein K, Korhonen H, Janicot M, Weber SN, et al. TGF-beta1 and TGF-beta2 abundance in liver diseases of mice and men. Oncotarget. 2016;7(15):19499-518.

37. Dash S, Sarashetti PM, Rajashekar B, Chowdhury R, Mukherjee S. TGF-beta2-induced EMT is dampened by inhibition of autophagy and TNF-alpha treatment. Oncotarget. 2018;9(5):6433-49.

\section{Figures}

a
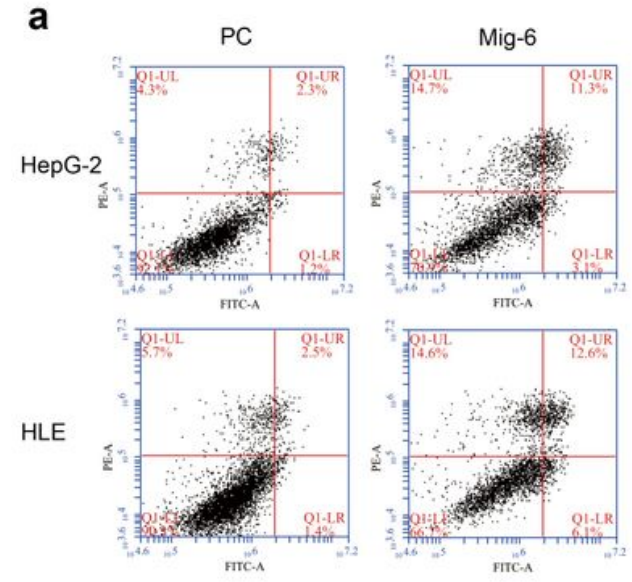
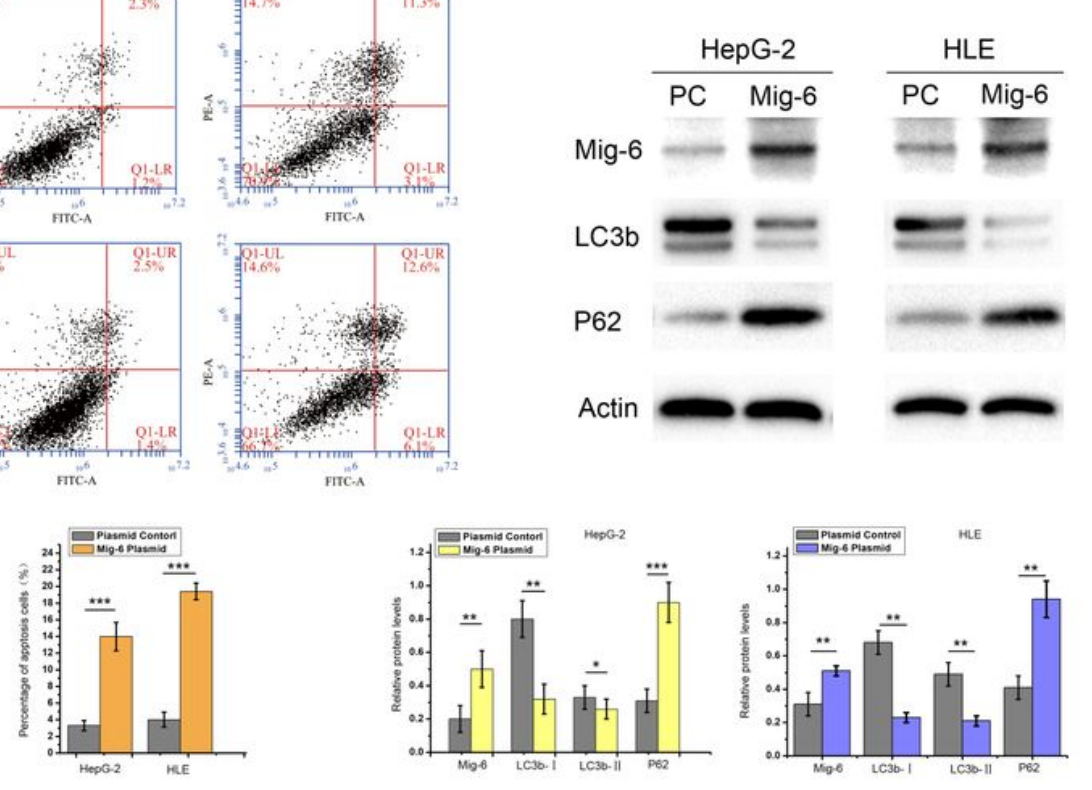

b

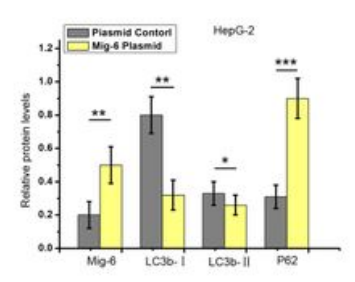

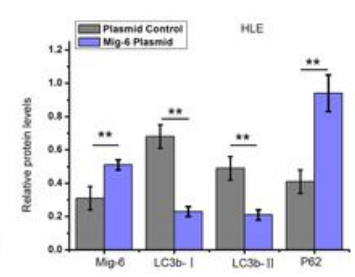

c
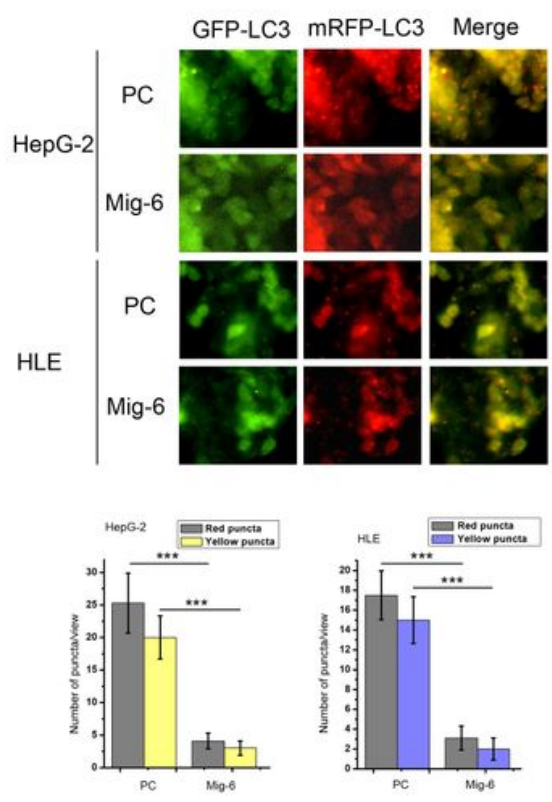

\section{Figure 1}

Effect of Mig-6 plasmid on the apoptosis and autophagy of HCC cell lines. a The apoptosis assay after 48h transfected with plasmid control and Mig-6 plasmid in HepG-2 and HLE cells, the percentage of apoptosis cells was quantified. b Western blotting and quantitative analysis of Mig-6, LC3b and p62 protein levels in HepG-2 and HLE cells. c Each group was transfected with a tandem mRFP-GFP-LC3 adenovirus for $24 \mathrm{~h}$. Autophagosomes and autolysosomes were, respectively, visualized as yellow- and red-only punctas under a fluorescence microscope. $\left({ }^{\star} P<0.05,{ }^{*} P<0.01,{ }^{\star * \star} P<0.001\right)$. 
a

Control virus
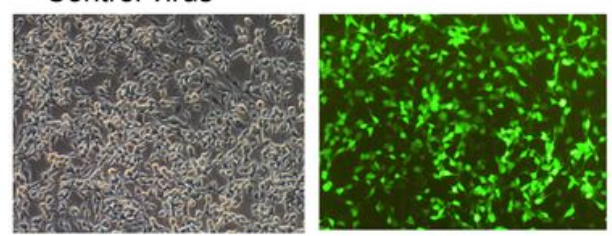

LV-Mig-6
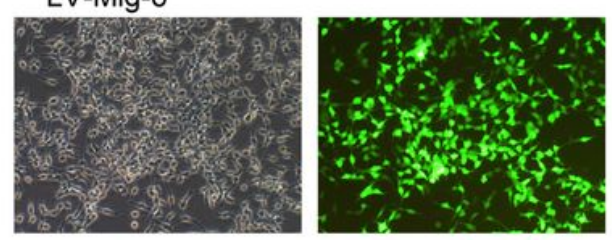

b

C

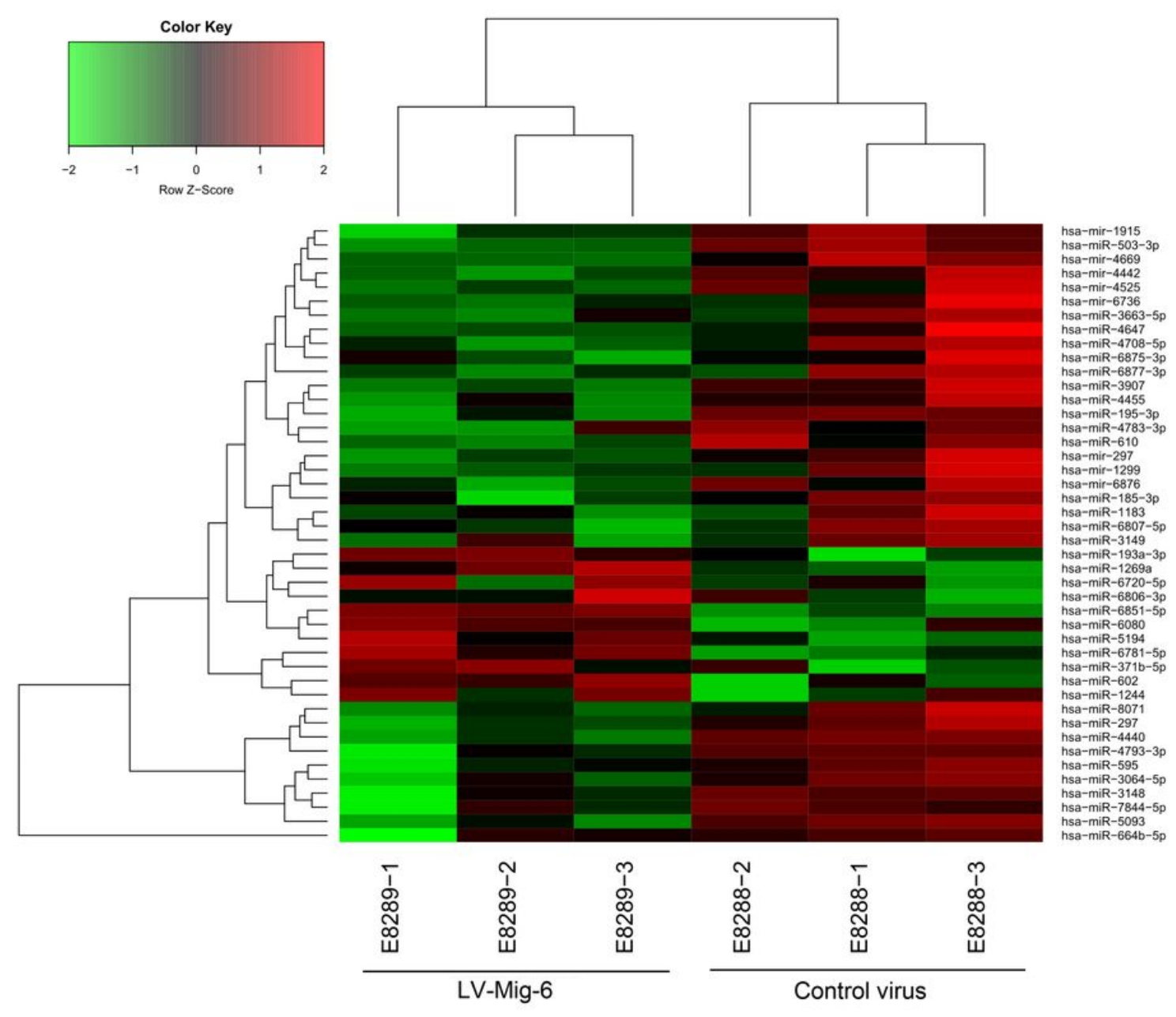

Figure 2

Prediction and confirmation of Mig- 6 regulated miRNAs. a Visualization of GFP expression in Control virus and LV-Mig- 6 group(100x) after 72h. b Western bloting and quantitative analysis of transduction efficiency of LV-Mig-6 in 293T cell lines. c Hierarchical cluster analysis of Mig-6-regulated miRNAs. The horizontal axis shows comparison groups of expression change of miRNAs. The left vertical axis shows clusters of Mig-6-regulated miRNAs whose fold change is listed in the right-hand table. Red indicates upregulated and green downregulated miRNAs. 
a

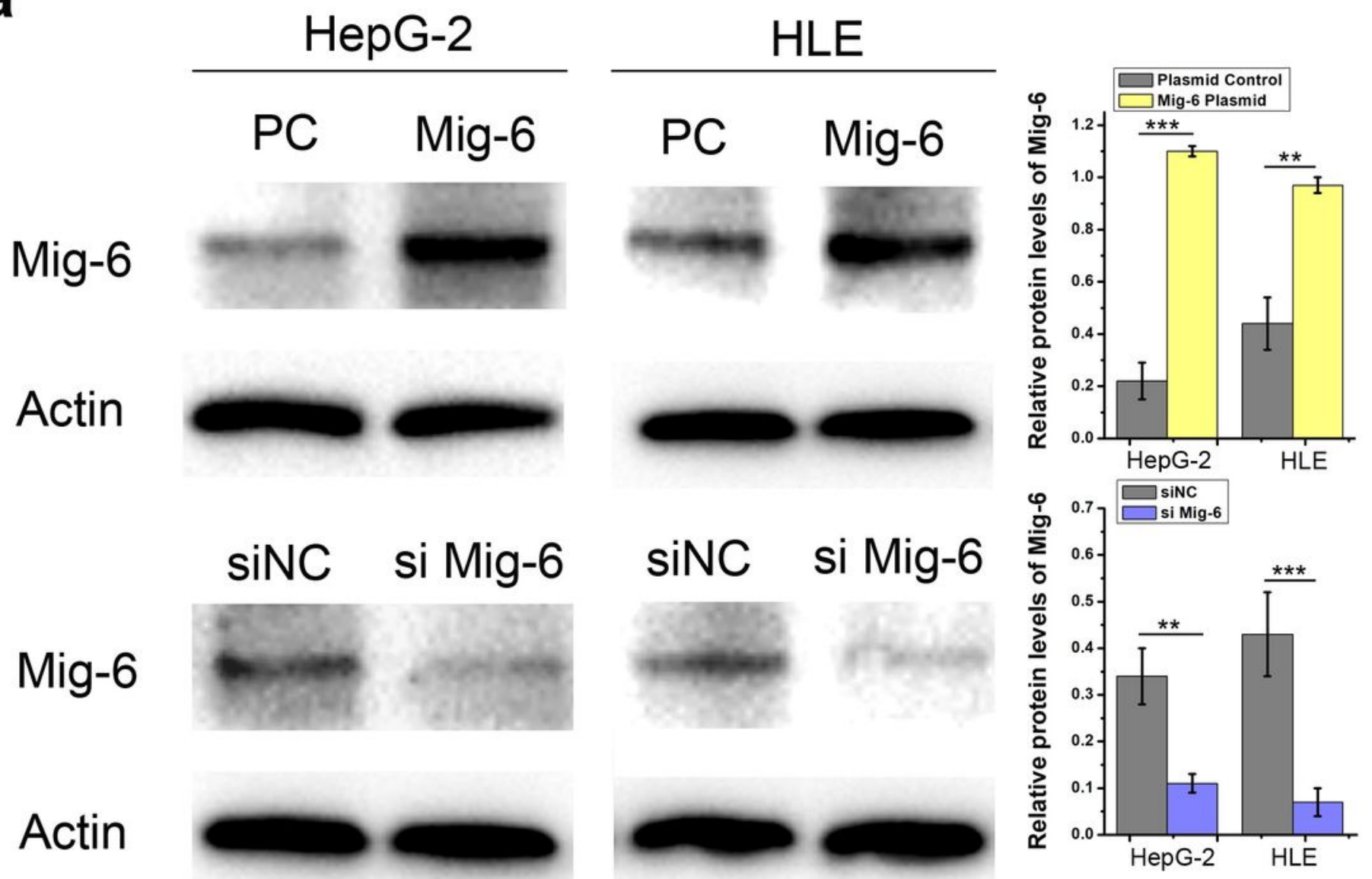

b
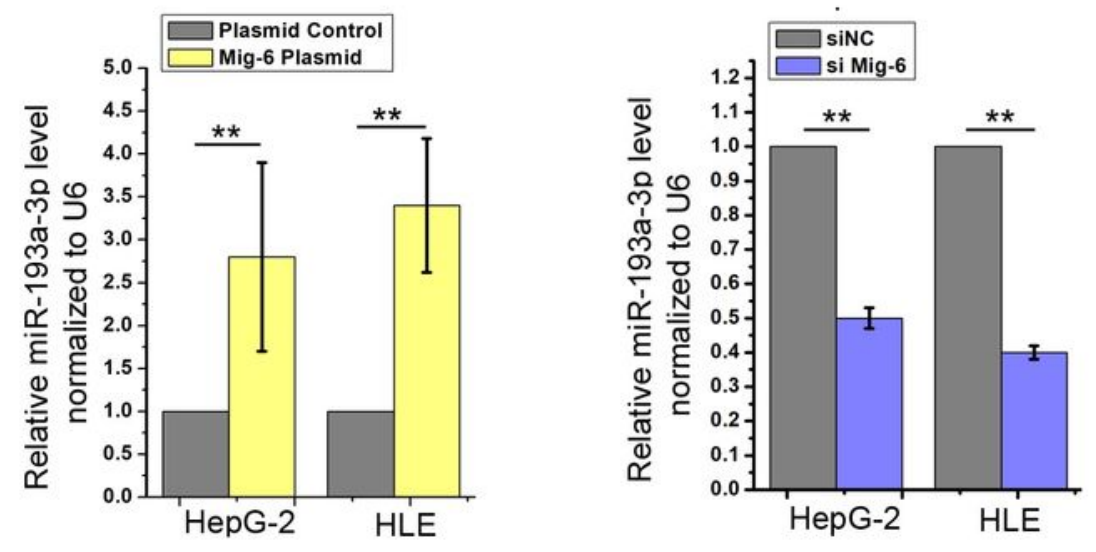

Figure 3

Confirmation of Mig- 6 regulated miRNAs. a Western bloting and quantitative analysis of transfection efficiency of Mig-6 plasmid and siMig- 6 in HepG-2 and HLE cell lines. b Quantitative RT-PCR analysis of the expression levels of miR-193a-3p in Mig- 6 up-regulate and down-regulate groups. ( ${ }^{\star \star P} P<0.01, \star \star \star P<$ $0.001)$. 
a

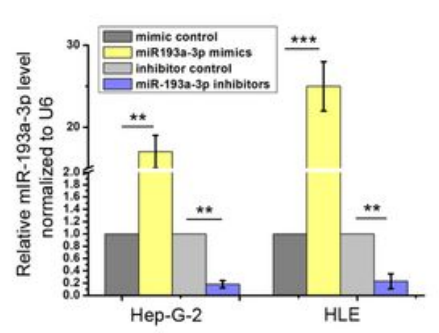

C

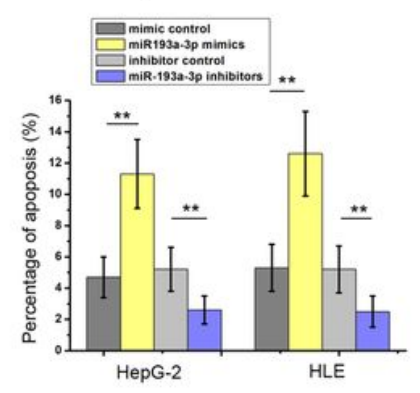

d

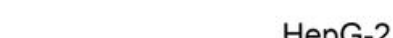

b

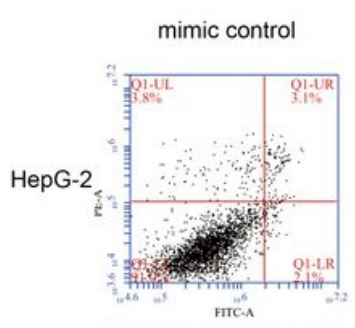

miR-193a-3p mimics

inhibitor control
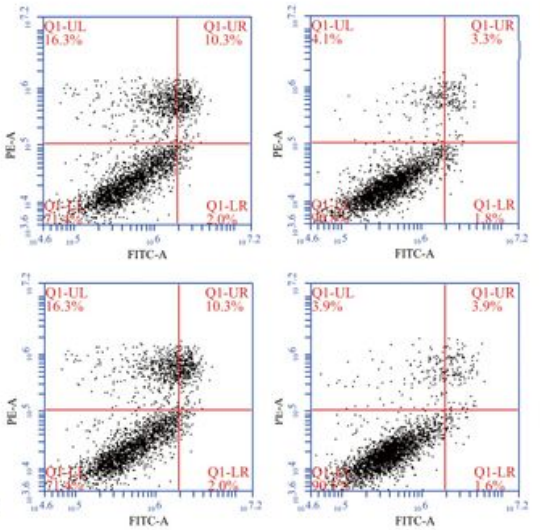

HLE

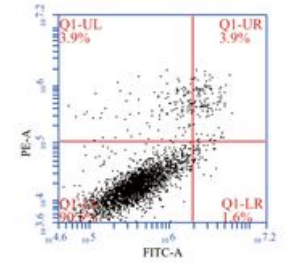

miR-193a-3p inhibitors
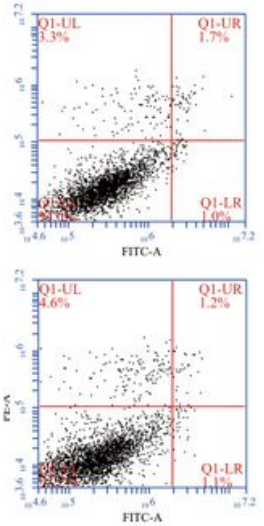

HepG-2

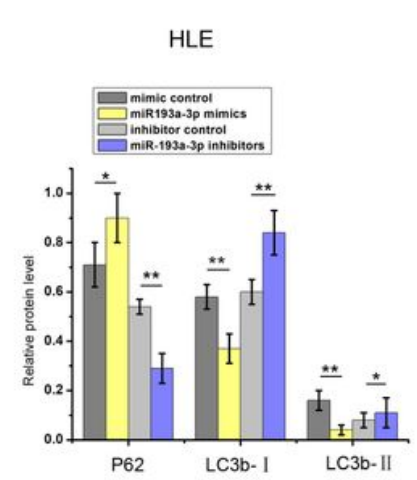

e

P62

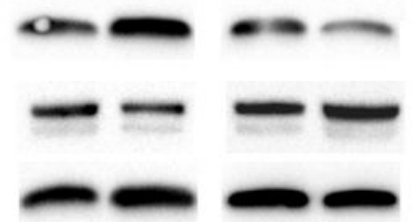
HLE

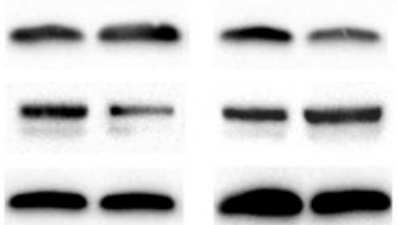

HepG-2

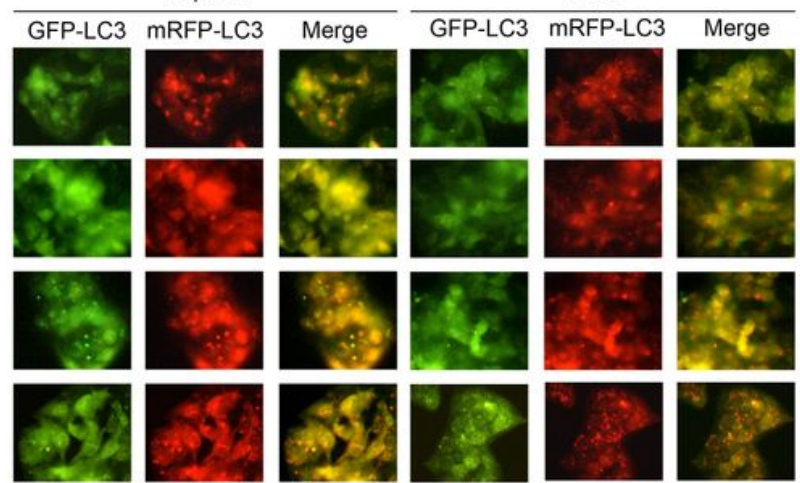

HepG-2

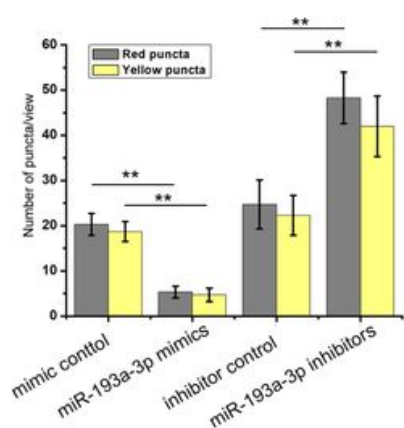

HLE

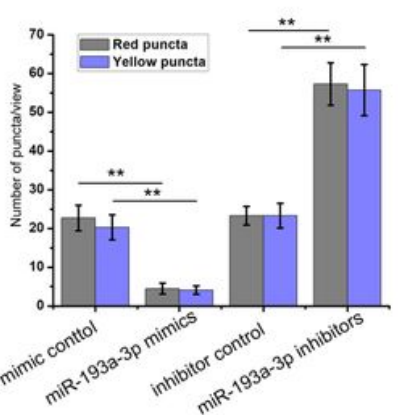

\section{Figure 4}

Effect of miR-193a-3p on the apoptosis and autophagy of HCC cell line. a Quantitative RT-PCR analysis of the expression levels of miR-193a-3p in HepG-2 and HLE cells transfected with miR-193a-3p mimics, inhibitors, and negative control. b , c The apoptosis assay 48h after four groups of HepG-2 and HLE cells transfected with equal doses of mimic control, miR-193a-3p mimics,inhibitor control and miR-193a-3p inhibitors,the percentage of apoptosis cells was quantified. $d$ Western blotting and quantitative analysis for Mig-6, LC3b and p62 expression $48 \mathrm{~h}$ after aforementioned four groups' transfection.in HepG-2 and HLE cells. e Each group was transfected with a tandem mRFP-GFP-LC3 adenovirus for $24 \mathrm{~h}$. 
Autophagosomes and autolysosomes were, respectively, visualized as yellow- and red-only punctas under a fluorescence microscope. $\left({ }^{*} P<0.05,{ }^{*} \mathrm{P}<0.01,{ }^{*} * \mathrm{P}<0.001\right)$.

a
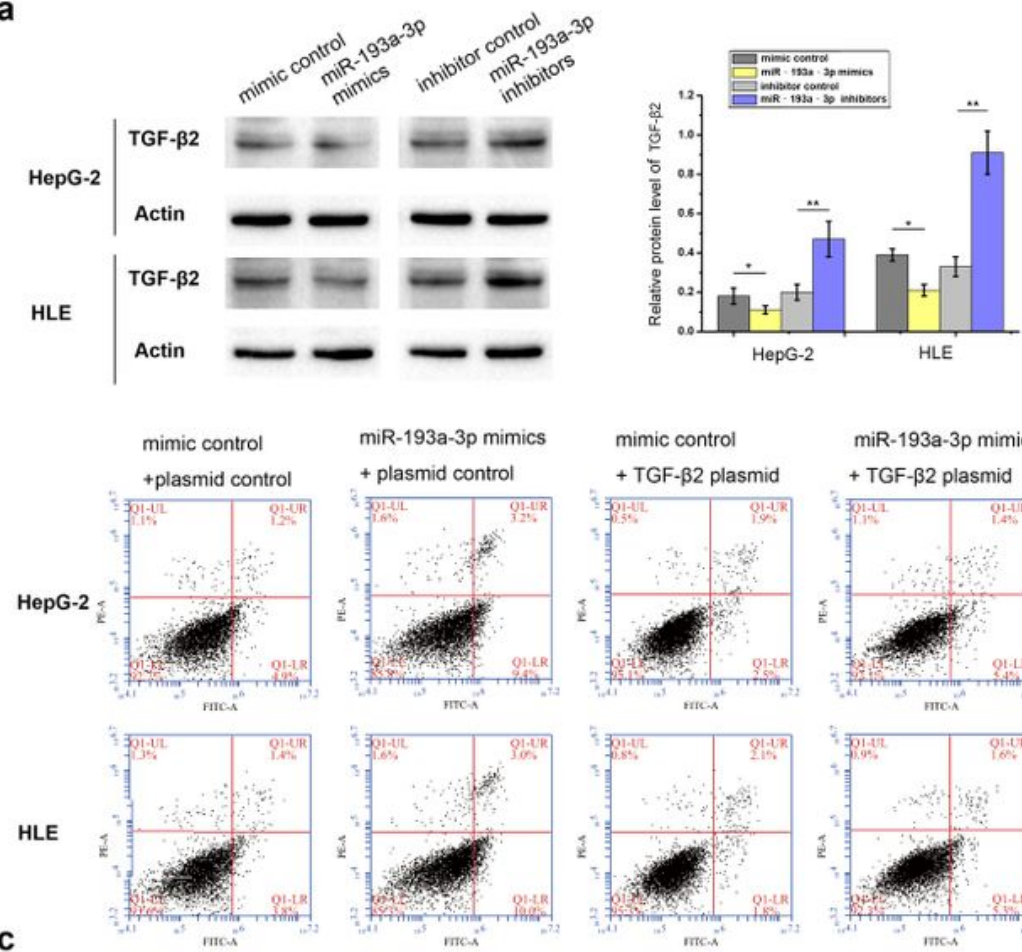

me
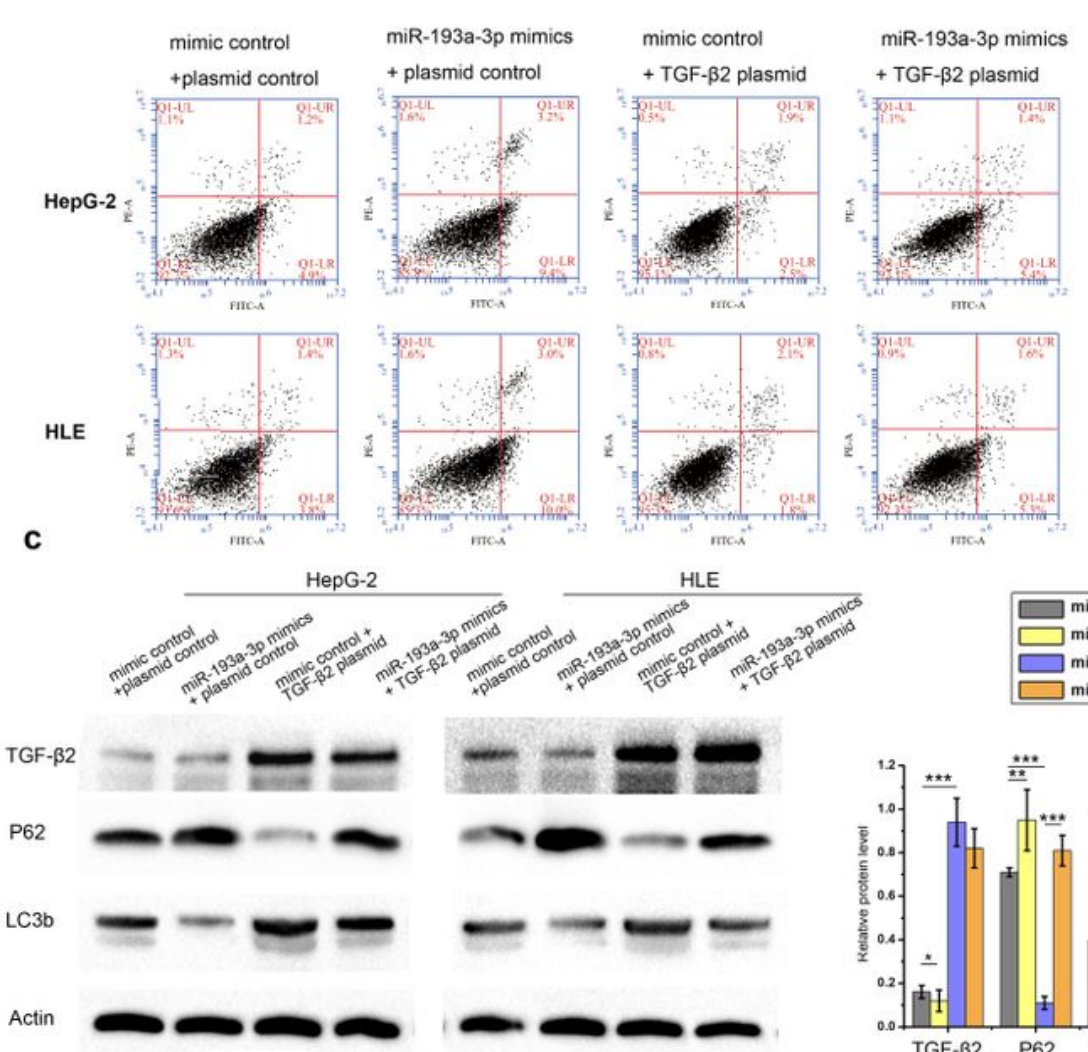

b
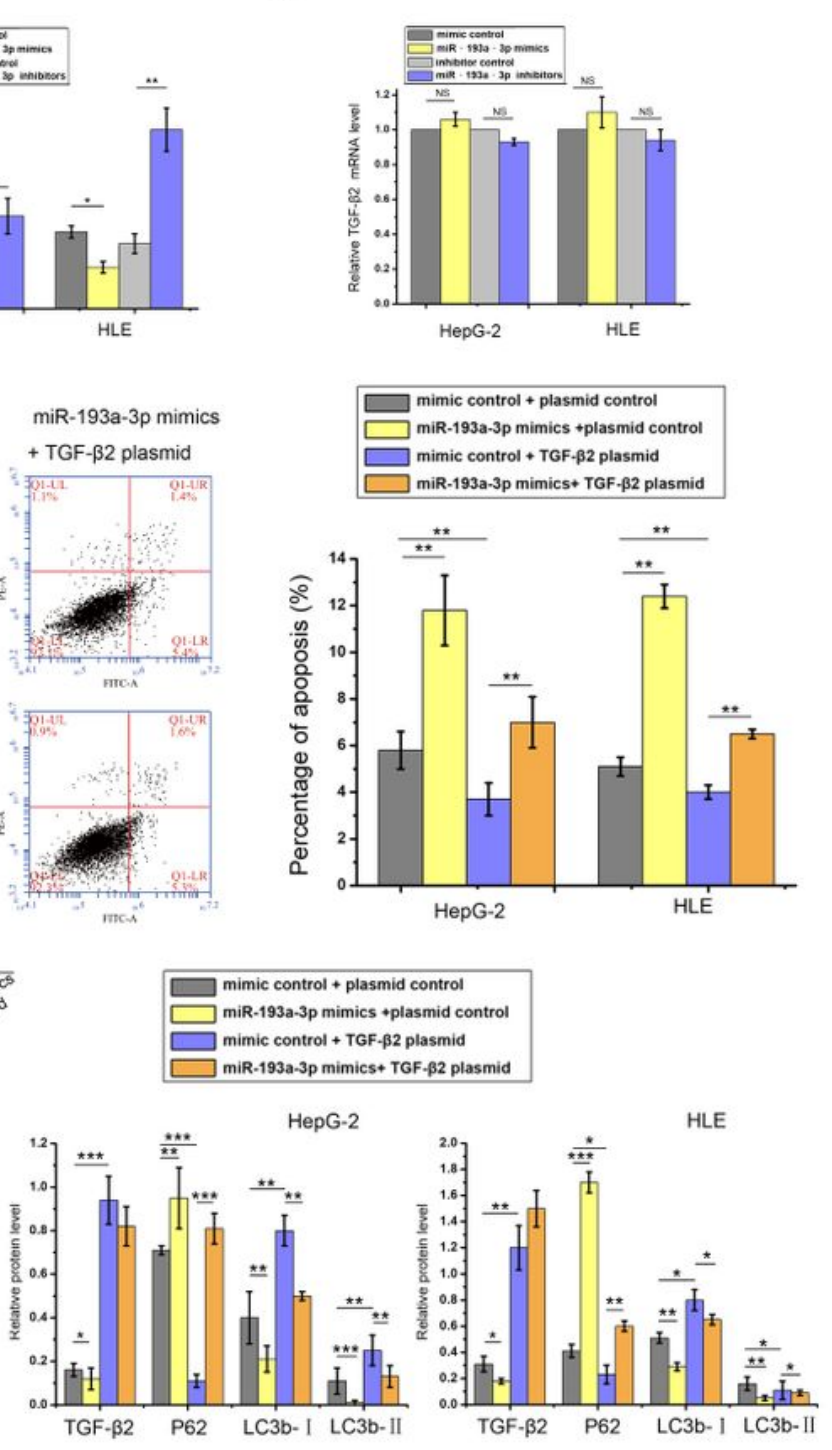

d
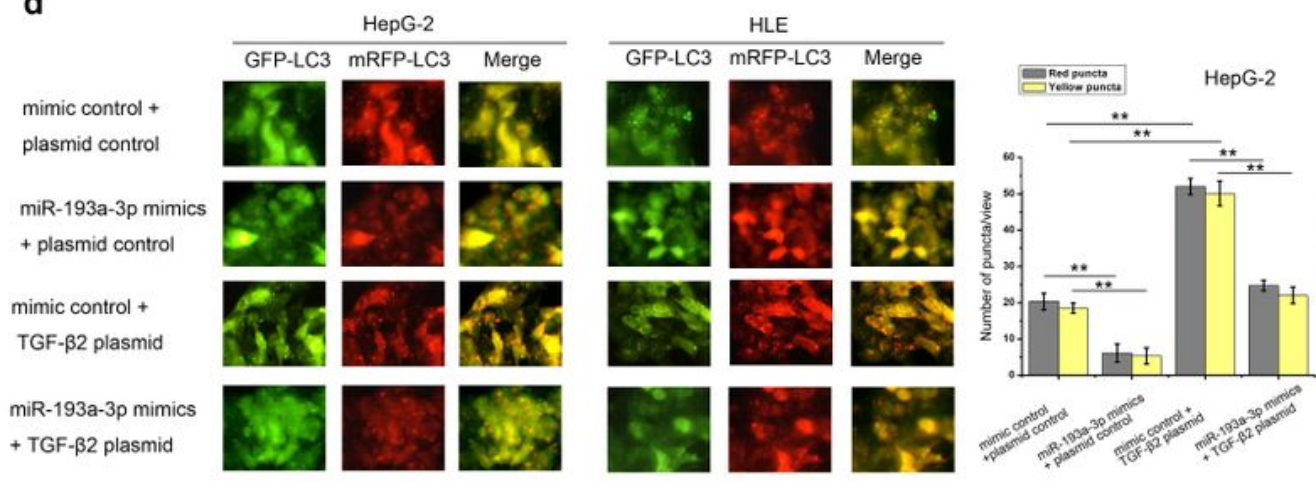

Red puncts
Yellow puncts

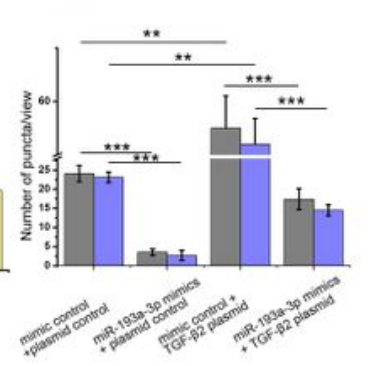

Figure 5

Effect of miR-193a-3p and TGF- 32 plasmid on the HCC cell lines. a Western blotting and the quantitative analysis of TGF- $\beta 2$ protein levels in HepG-2 and HLE cells after transfected with equal doses of the miR193a-3p mimics, inhibitors, and negative control. b Quantitative RT-PCR analysis of the expression levels 
of TGF- $\beta 2$ mRNA in HepG-2 and HLE cells transfected with miR-193a-3p mimics, inhibitors, and negative control. c The apoptosis assay 48h after four groups of HepG-2 and HLE cells transfected with equal doses of mimic control plus plasmid control, miR-193a-3p mimics plus plasmid control,mimic control plus TGF- $\beta 2$ plasmid and miR-193a-3p mimics plus TGF- $\beta 2$ plasmid, the percentage of apoptosis cells was quantified. $d$ Western blotting and quantitative analysis for TGF- $\beta 2$, LC3b and p62 expression $48 \mathrm{~h}$ after aforementioned four groups' transfection in HepG-2 and HLE cells. e Each group was transfected with a tandem mRFP-GFP-LC3 adenovirus for $24 \mathrm{~h}$. Autophagosomes and autolysosomes were, respectively, visualized as yellow- and red-only punctas under a fluorescence microscope. ${ }^{\star} \mathrm{P}<0.05$, ${ }^{\star \star} \mathrm{P}<$ $0.01, * \star * P<0.001)$.

a

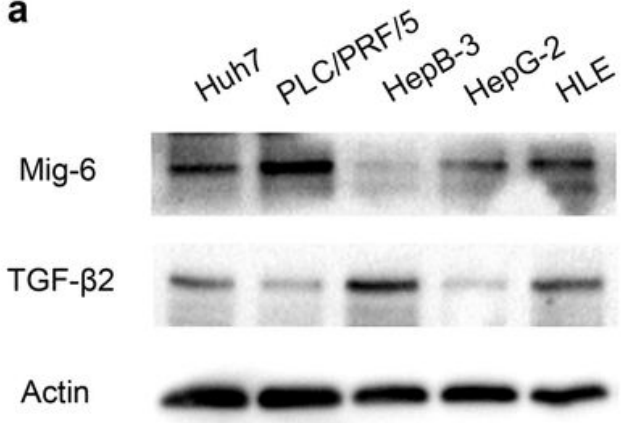

C

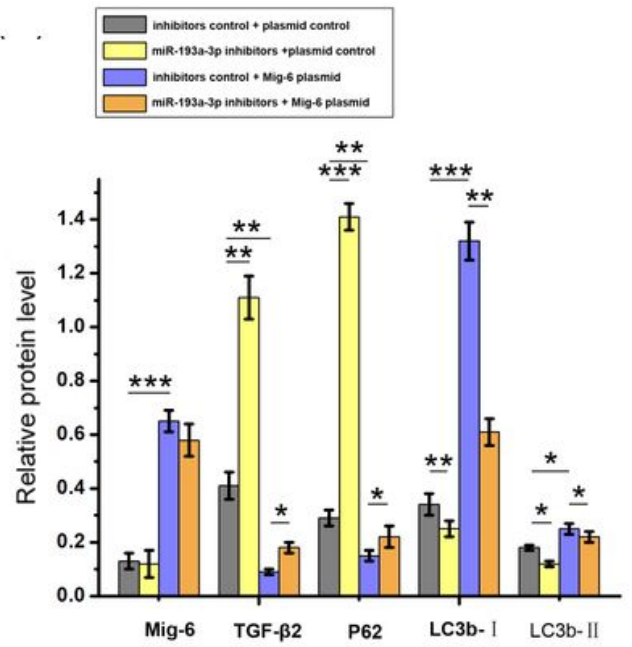

e

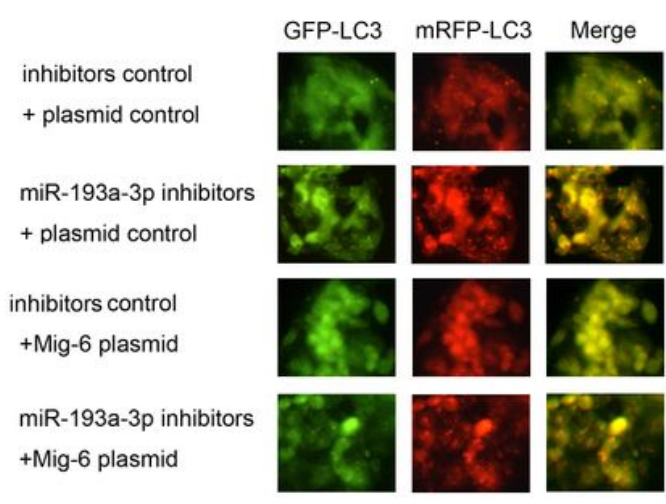

b
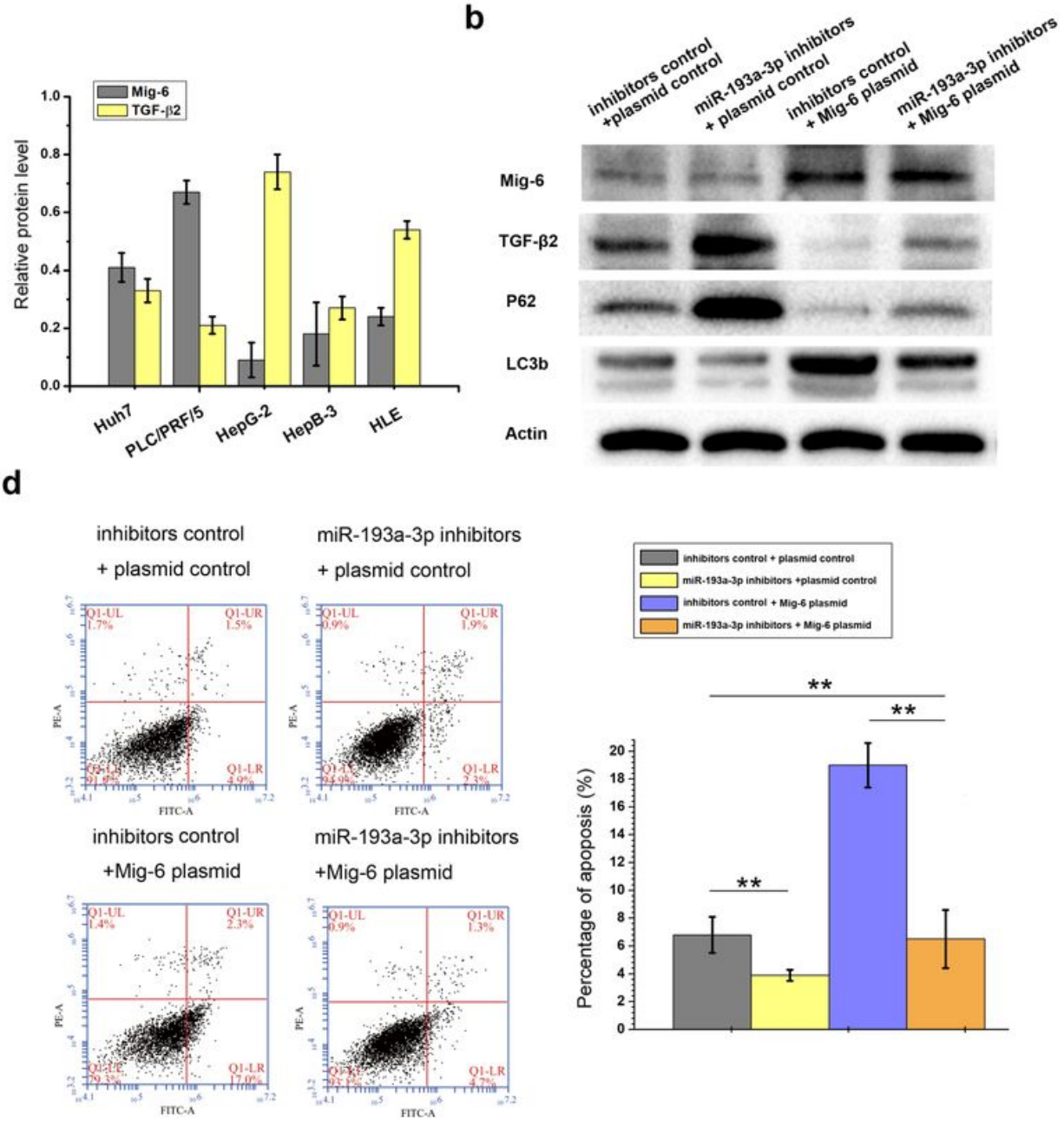

miR-193a-3p inhibitors
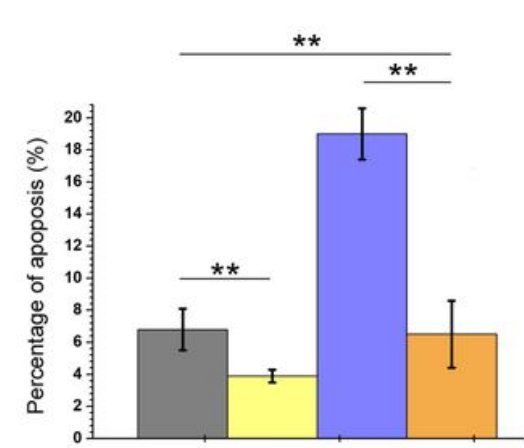

+ plasmid control

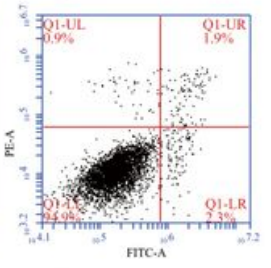

miR-193a-3p inhibitors +Mig-6 plasmid
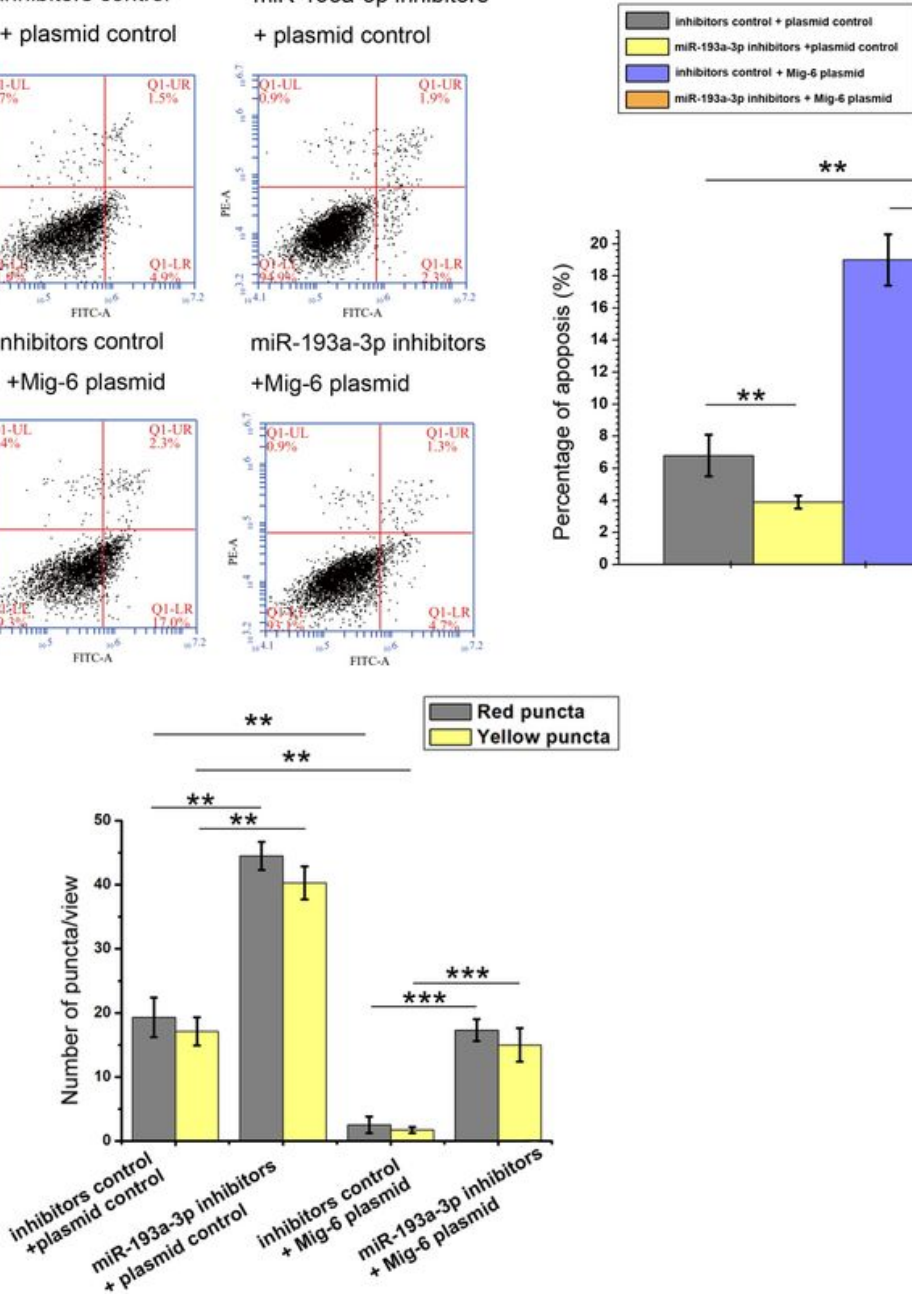


\section{Figure 6}

Relationship between miR-193a-3p and TGF- $\beta 2$, and the effect of Mig- 6 plasmid and miR-193a-3p inhibitors on TGF- $\beta 2$. a The correlation of Mig- 6 and TGF- $\beta 2$ in HCC cell lines. b,c, The apoptosis assay $48 \mathrm{~h}$ after forementioned four groups' transfection in HLE cells. $\mathrm{d}$ Western blotting and quantitative analysis for Mig-6,TGF- $\beta 2$, LC3b and p62 expression 48h after four groups of HLE cells transfected with equal doses of inhibitor control plus plasmid control, miR-193a-3p inhibitors plus plasmid control, inhibitor control plus Mig-6 plasmid, and miR-193a-3p inhibitors plus Mig-6 plasmid. e Each group was transfected with a tandem mRFP-GFP-LC3 adenovirus for $24 \mathrm{~h}$. Autophagosomes and autolysosomes were, respectively, visualized as yellow- and red-only punctas under a fluorescence microscope. $\left({ }^{\star} \mathrm{P}<0.05,{ }^{\star *} \mathrm{P}<0.01,{ }^{\star * *} \mathrm{P}<0.001\right)$.

\section{Supplementary Files}

This is a list of supplementary files associated with this preprint. Click to download.

- SupplementTable1.docx 